\title{
Senecavirus A: An emerging pathogen causing vesicular disease in pigs
}

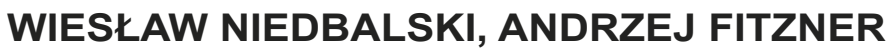

Department of Foot-and-Mouth Disease, National Veterinary Research Institute, Wodna 7, 98-220 Zduńska Wola, Poland

\section{Niedbalski W., Fitzner A. \\ Senecavirus A: An emerging pathogen causing vesicular disease in pigs}

Summary

Senecavirus A (SVA) is a single representative species of the Senecavirus genus within the family Picornaviridae. This review presents the current knowledge regarding SVA epidemiology, transmission, pathogenesis, clinical signs, differential diagnosis and control measures. SVA is not debilitating, but significant because of its resemblance to acute, highly contagious and economically devastating viral diseases, such as FMD. The incubation period of SVA is 4-5 days, the viremia period is short, lasting 3 to 10 days post infection (dpi). SVA shedding lasts up to 28 days. SVA can be shed by oral and nasal secretions and by faeces. The virus excretion peak occurs between 1 and 5 dpi, especially in oral secretions, which contain higher virus loads relative to nasal secretions and faeces. SVA lesions are found most frequently on the snout, lips and tongue, as well as on hooves, specifically, on coronary bands, dewclaws, hoof pads and in interdigital space. The vesicles quickly rupture to form ulcers that may be covered by serofibrinous exudates. The ulcers begin to repair in 7 days, and the regeneration of epithelium is usually complete within 2 weeks. Since clinical lesions induced by SVA are indistinguishable from those observed in other vesicular diseases of swine, accurate and reliable laboratory differential diagnosis is critical to the precise identification of the infectious agent. SVA has potential cytolytic activity and high selectivity for tumour cell lines with neuroendocrine properties versus adult normal cells. Because of its potential oncolytic activity, the virus can be useful in human cancer therapy. The example of SVA shows that the risk of emerging infectious diseases in swine populations is high and that emerging diseases of swine have significant potential impact on the productivity and economics of the pork industry. The SVA infection is currently limited to the United States, Canada, Brazil, China and Thailand. However, descriptions of the SVA infection in Asia suggest that the virus is not restricted to a specific geographic region and may be distributed on a global scale in the future.

Keywords: Senecavirus A, swine, emergent vesicular disease, oncolytic virotherapy

Senecavirus A (SVA) is a single representative species of the Senecavirus genus within the family Picornaviridae (International Committee on Taxonomy of Viruses, http://www.ictvonline.com). The virus was isolated in the laboratories of Neotropix, Inc., near Seneca Creek State Park, Gaithersburg, Maryland, the United States, in 2002 from the PER. C6 cell line, which had been derived from human embryonic retinal cells (11). This new pathogen was named Seneca Valley virus 001 (SVV-001) from the place of isolation (28). It was assumed that this pathogen could have been introduced into the cell culture through the use of contaminated fetal bovine serum or porcine trypsin (11). SVV was not associated with disease until 2007, when it was first observed in pigs with idiopathic vesicular disease (11). The term Porcine Idiopathic Vesicular Disease (PIVD) has been used to designate infrequent cases in which, with unknown cause, swine display erosions and vesicles on the skin, snout, oral cavity and coronary bands (4). These cases have been found in several regions of the world: the United States (8), Australia (21), New Zealand (18) and Italy (29). In all these cases, the well-known animal vesicular diseases, such as foot-and-mouth disease (FMD), swine vesicular disease (SVD), vesicular stomatitis (VS) and vesicular exanthema of swine (VES), were ruled out on the basis of laboratory diagnosis. Moreover, approximately $80 \%$ of pigs that were transported from Manitoba (Canada) to the United States presented vesicular lesions that were indistinguishable from those of vesicular animal diseases and were tested with negative results for the presence of those diseases. However, SVV RNA was detected in biological samples and was proposed as the etiological agent of the vesicular disease of those pigs (22). In 2012, the second detection of SVV occurred in Indiana, the United States, in a single 6-month- 
-old-animal with vesicular symptoms (30). Both these reports suggested that this pathogen could be associated with PIVD. In the beginning of 2015, outbreaks of Senecavirus A in weaned and adult pigs occurred in six southern Brazilian states in three geographical regions (16). At the same time, increased mortality rates of newborn pigs at 1 to 4 days of age were recorded in the main Brazilian pig producing regions. Clinical signs in affected piglets included lethargy, cutaneous hyperaemia, diarrhoea and neurological signs (15). The affected piglets that died spontaneously were tested negative for different vesicular infectious agents, and SVA was investigated in biological samples from the piglets, with positive results being observed in faeces, serum and diverse organs $(15,16)$. In 2015, this vesicular disease was first reported in the Guangdong province in China, and the results of laboratory diagnosis of samples from these outbreaks presented positive results for SVA(33). Disease was manifested by typical vesicular lesions, and sudden death in newborn piglets was observed. Since 2015, an increased number of SVA vesicular disease outbreaks have been reported in the United States, but the virus infection in that country has also been associated with neonatal mortality of pigs, especially in herds with vesicular disease-affected sows (5). In 2016, pig herds from Canada (Ontario) and Thailand were also affected by SVA infection. The full-light genome sequence demonstrated that Thailand isolates were closely related to the first Canadian strain of SVA (26).

Senecavirus A has some features in common with all picornaviruses, such as a noneveloped capsid that is about 25 to $30 \mathrm{~nm}$ in diameter with icosahedral symmetry and a single-stranded positive-sense RNA of approximately $7.2 \mathrm{~kb}(11)$. The SVA genome encodes a large single open reading frame that is expressed as a polyprotein precursor. The 5 'portion of the polyprotein is flanked by an untranslated region (5'UTR) of 666 nucleotides (nt) and a shorter polyadenylated untranslated region 3'end (3'UTR) of 71 nt. An analysis of the nt sequence within 5'UTR of SVA revealed high levels of secondary structures (1). This untranslated region of the SVA genome has an internal ribosome entry site (IRES), the function of which is to allow independent translation of viral RNA by inhibiting the translation of cellular RNA. The virus genome consist of the leader (L) and three major protein regions, named polyproteins 1 to $3(\mathrm{P} 1, \mathrm{P} 2$ and $\mathrm{P} 3)$. The $\mathrm{P} 1$ region is cleaved into structural polypeptides VP0, VP3 and VP1, which are proteins that compose the virus capsid. A maturation site located within VP0 gives VP2 and the internal VP4 polypeptide. The P2 and P3 genome regions encode non-structural polypeptides involved in protein processing and are associated with viral replication. The $\mathrm{P} 2$ region is divided into $2 \mathrm{~A}, 2 \mathrm{~B}$ and $3 \mathrm{C}$ polypeptides. The $2 \mathrm{~A}$ protein is a short peptide of 9 aa with a predicted ribosome-skipping function. The $2 \mathrm{~B}$ protein presumably plays a role in enhancing mem- brane permeability, and the $2 \mathrm{C}$ protein is a helicase-like polypeptide involved in RNA synthesis. The $\mathrm{P} 3$ region possesses 3A, 3B, 3C and 3D polypeptides. The 3B region encodes a VPg protein that acts as a primer for RNA synthesis, $3 \mathrm{C}$ is a proteinase, and $3 \mathrm{D}$ is a major component of RNA-dependent RNA polymerase (11).

Since 2015, the molecular epidemiology of SVA has been limited to strains from the United States and Canada (11). After detection of SVA in Brazil and the increasing incidence of the disease in Brazil, China, the United States, Canada and Thailand in 2015, complete and partial genomic sequences of SVA isolates were established in most of these countries. The complete genomic sequences of SVA strains from 2015 and 2016 showed a high nucleotide percentage identity $(95.8 \%$ to $99.9 \%$ ) between them and about $97 \%$ amino acid identity with the prototype strain SVV-001 (10, 31, $33,35)$. Based on the nucleotide sequence of the VP1 region of SVA strains, a phylogenetic tree was constructed, and three temporal clades of SVA were identified $(9,28)$. Clade I contains the initially identified SVA strains, with the prototype SVV-001, clade II includes the U.S. Senecavirus strains identified between 1988 and 1997, and clade III contains the SVA strains from Brazil, Canada, China, Thailand and the United States identified between 2001 and 2016. Despite the divergence between historical and contemporary SVA strains, it remains unknown whether genetic changes in the Senecavirus genome have led to changes in the biological behaviour of the virus and contributed to the emergence of SVA infections (9).

SVA is not debilitating, but significant because of its resemblance to acute, highly contagious and economically devastating viral diseases, such as FMD. Judging by the available data on the disease naturally occurring in the United States and Brazil, clinical SVA infection in pigs presents similar characteristics, but clinical signs and lesions are relatively mild, although indistinguishable from FMD and other porcine vesicular diseases: SVD, VS and VES (16). The incubation period for SVA is $4-5$ days $(12,19)$. The tonsil is indicated as one of the primary sites of Senecavirus replication during the acute stage of infection. The viraemia period is short, lasting 3 to 10 days post inoculation (dpi), whereas virus shedding was detected between days 1 and 28 pi in oral and nasal secretions and in faeces (12) (Fig. 1). The virus excretion peak occurs between 1 and 5 dpi, especially in oral secretions, which contain higher virus loads relative to nasal secretions and faeces. Additionally, infectious SVA particles were isolated from oral secretions up to $21 \mathrm{dpi}$, from faeces up to $10 \mathrm{dpi}$, and from nasal secretions up to $7 \mathrm{dpi}$ (12). The post-mortem lesions of SVA include multifocal, round, discrete erosive and ulcerative lesions on distal limbs, especially around the coronary bands (30). Crusting and sloughing of the hoof wall may also be observed. Fluid-filled vesicles and multifocal chronic superficial and deep ulcers 


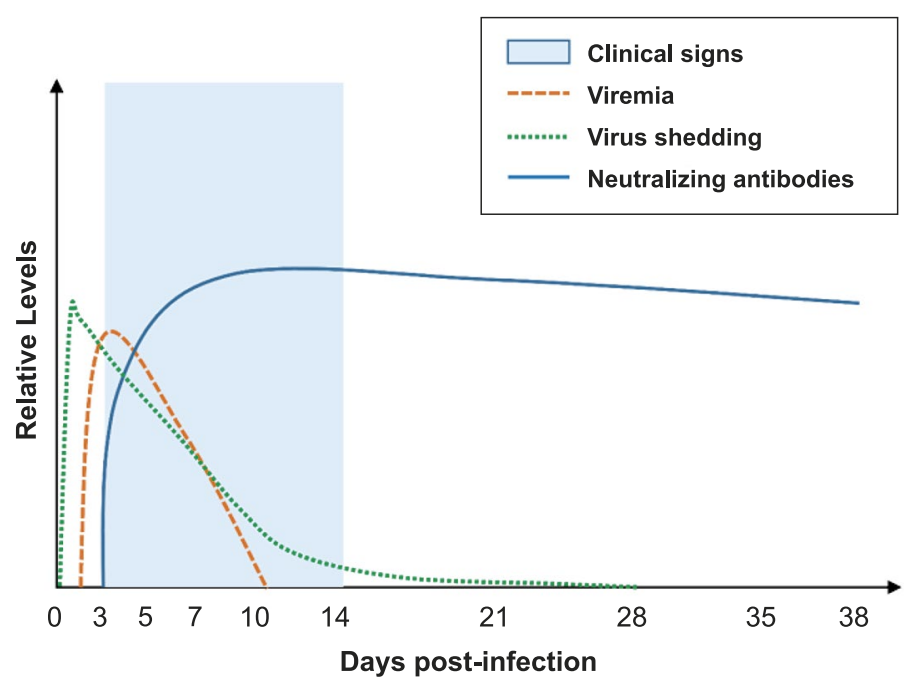

Fig. 1. Infection dynamics of SVA in pigs. Modified, according to Joshi et al. (12)

have also been described in and around the oral mucosa, snout and nostrils. Serofibrinous peritonitis and pericarditis, locally extensive hemorrhagic jejunitis and focal gastric ulcers have been reported in infected pigs (30). The ulcers begin to repair in 7 days, and regeneration of epithelium is usually complete within 2 weeks (Fig. 1). Vesicles and erosions associated with SVA infection are seen mainly in sows and fattening pigs. Lesions may be preceded by a short period of hyperthermia $\left(40.3^{\circ} \mathrm{C}-40.8^{\circ} \mathrm{C}\right)$, lameness and anorexia (12). SVA outbreaks presented morbidity rates of $0.5 \%$ to $5 \%$ in weaned pigs and $5 \%$ to $30 \%$ in finishing pigs and breeders $(16,28)$. Microscopic tissue alterations in experimentally infected pigs were restricted to the tonsils, the spleen, lymph nodes and the lungs, and consisted of mild to moderate lymphoid hyperplasia in lymphoid tissue, infiltration by neutrophils together with fibrin, oedema, acute haemorrhage, multifocal mild atelectasis and occasionally diffuse congestion, with a multifocal mild perivascular accumulation of lymphocytes, plasma cells and macrophages in the lungs $(12,30)$. The presence of viral RNA and infectious particles was found in the lungs, the mediastinal and mesenteric lymph nodes, the liver, the spleen, the small and large intestines and the tonsils during the acute phase of disease (12). In newborn pigs, morbidity and mortality rates are considerably higher, especially in one- to four-day-old piglets, with morbidity rates of up to $70 \%$ and the mortality rates from $15 \%$ to $30 \%$ (1, $5,15,28)$. At post-mortem examination, a significant percentage $(5-27 \%)$ of piglets with diarrhoea showed subcutaneous or mesenteric oedema, and most piglets had milk in the stomach. The contents of the small and large intestines were voluminous with a fluid consistency, without noticeable gross or microscopic lesions of the mucosa (28).

The humoral immune response plays an important role in the clearance of picornaviruses from infected animals. Studies that evaluated the immunological response against SVA indicate that the virus infection induces an early immunological response in clinically affected and non-affected sows under field conditions (9) and in experimentally challenged finishing pigs $(12,19)$. Seroconversion to SVA occurs approximately 5 dpi, regardless of the clinical manifestations of the disease, and neutralizing antibody titres peak around 14 dpi (Fig. 1). The increase in neutralizing antibody titres occurs simultaneously with decreasing disease severity, viral load in tissue, viraemia and virus shedding, which suggests that antibody responses lead to the progressive clearance of SVA from the circulation and most organs, excretions and secretions $(9,12)$. The role and importance of the cellular immunity to SVA remain unknown. Chen et al. (6) demonstrated only a minimal level of IFN-alpha production by $3 \mathrm{dpi}$, while IFN-gamma was undetectable in SVA-infected animals.

The clinical resemblance of VSA to FMD and other porcine vesicular diseases (Tab. 1) highlights the need for its reliable identification and discrimination. Of the diseases associated with vesicular lesions in swine, FMD is of primary concern given its highly infectious nature, broad host range and importance to international trade. A detection of vesicular lesions in pigs often initiates screening studies for a foreign animal disease in FMD-free countries, and herds should be considered affected by FMD until proven otherwise.

Tab. 1. Viruses that cause indistinguishable vesicular lesions in pigs

\begin{tabular}{|c|c|c|c|}
\hline Virus & $\begin{array}{l}\text { Virus family } \\
\text { and genus }\end{array}$ & $\begin{array}{l}\text { Location of } \\
\text { vesicles }\end{array}$ & $\begin{array}{l}\text { Species } \\
\text { affected }\end{array}$ \\
\hline $\begin{array}{l}\text { Foot-and-mouth } \\
\text { disease virus } \\
\text { (FMDV) }\end{array}$ & $\begin{array}{l}\text { Picornaviridae, } \\
\text { Aphtovirus }\end{array}$ & $\begin{array}{l}\text { Snout } \\
\text { Oral mucosa } \\
\text { Tongue } \\
\text { Pharynx } \\
\text { Coronary bands } \\
\text { Interdigital space } \\
\text { Teats }\end{array}$ & $\begin{array}{l}\text { Cloven-hoofed } \\
\text { animals }\end{array}$ \\
\hline $\begin{array}{l}\text { Swine vesicular } \\
\text { disease (SVDV) }\end{array}$ & $\begin{array}{l}\text { Picornaviridae, } \\
\text { Enterovirus }\end{array}$ & $\begin{array}{l}\text { Snout } \\
\text { Oral mucosa } \\
\text { Tongue } \\
\text { Pharynx } \\
\text { Coronary bands } \\
\text { Hooves } \\
\text { Heels }\end{array}$ & Swine \\
\hline $\begin{array}{l}\text { Vesicular stomatitis } \\
\text { (VSV) }\end{array}$ & $\begin{array}{l}\text { Rhabdoviridae, } \\
\text { Vesiculovirus }\end{array}$ & $\begin{array}{l}\text { Snout } \\
\text { Oral mucosa } \\
\text { Tongue } \\
\text { Pharynx } \\
\text { Coronary bands } \\
\text { Interdigital space } \\
\text { Heels } \\
\text { Teats }\end{array}$ & $\begin{array}{l}\text { Swine } \\
\text { Cattle } \\
\text { Horses }\end{array}$ \\
\hline $\begin{array}{l}\text { Vesicular } \\
\text { exanthema of swine } \\
\text { (VESV) }\end{array}$ & $\begin{array}{l}\text { Caliciviridae, } \\
\text { Vesivirus }\end{array}$ & $\begin{array}{l}\text { Snout } \\
\text { Oral mucosa } \\
\text { Tongue } \\
\text { Pharynx } \\
\text { Coronary bands } \\
\text { Interdigital space } \\
\text { Heels }\end{array}$ & $\begin{array}{l}\text { Swine } \\
\text { Pinnipeds }\end{array}$ \\
\hline $\begin{array}{l}\text { Senecavirus A } \\
\text { (SVA) }\end{array}$ & $\begin{array}{l}\text { Picornaviridae, } \\
\text { Senecavirus }\end{array}$ & $\begin{array}{l}\text { Snout } \\
\text { Oral mucosa } \\
\text { Coronary bands }\end{array}$ & Swine \\
\hline
\end{tabular}


FMD-affected pigs develop vesicular lesions indistinguishable from those caused by SVA. Importantly, FMD can cause myocarditis in young animals, which is not observed in piglet mortality attributed to SVA infection. SVD virus in pigs also causes lesions with similar appearance to those caused by SVA, but since 2015 it has been recognized by OIE as eradicated in the world. VS virus in cattle and pigs also causes lesions similar to those caused by SVA (Tab. 1). One notable difference is the susceptibility of horses to VSV infection. Thus the observation of affected horses in an outbreak may help narrow the differential diagnosis. VS occurs in both endemic and epidemic forms and is currently limited to the Americas. VES virus, a calicivirus, induces an acute febrile disease of swine, also clinically indistinguishable from SVA. The occurrence of VES was limited to the United States, but in 1959 the country was declared free of VES.

Since clinical lesions induced by SVA are indistinguishable from those observed in other vesicular diseases of swine, a fast, sensitive and accurate laboratory differential diagnosis is critical to the precise identification of the infectious agent. Currently, many diagnostic tests are available for the detection of SVA infection in pigs. The dynamics of infection and viraemia, patterns of virus shedding and viral load and tissue distribution can be assessed by conventional and real-time RT-PCR $(2,5,16,32)$, as well as the next-generation sequencing (NSG) technology $(7,31)$. One disadvantage of diagnosing SVA by molecular assays may be inconsistent detection due to the progression of SVA infection, with variations in viral shedding and load in different biological samples (9). Blood, vesicular fluid and epithelial tissue are typically collected for diagnostic studies. During initial diagnosis, other causes of vesicular disease can be ruled out by SVA isolation in different cell lineages, such as swine tests (ST), swine kidney (SK-RST and PK-15), baby hamster kidney (BHK-21) cells and human retinoblast (PER.C6) cells, as well as human lung cancer cell monolayers (NCI-H1299) $(24,34)$. The last cell monolayer was the most susceptible to SVA infection and produced a high virus titre $\left(10^{9} \mathrm{PFU} / \mathrm{ml}\right) 24$ hours after infection (34). Other diagnostic techniques currently available include immunohistochemical and in situ hybridization, which are assays that identify specific SVA antigens and nucleic acid in tissue samples, respectively $(12,15)$. The presence of antibodies to SVA may indicate previous infection and the possible presence of the virus in the herd. Antibody detection methods used for SVA screening in pigs are the indirect fluorescent antibody test (IFA), virus neutralization (VN) tests (27) and indirect or competitive ELISA $(9,34)$.

The transmission route(s) for Senecavirus A have not been well established. FMDV, a related picornavirus that causes similar disease, is transmitted through the direct contact of infected animals, contaminated objects or by inhalation of aerosolized viral particles (23).
FMDV-infected animals shed the virus through all their body secretions and excretions. It is not known whether the same is true for SVA. It has been shown, however, that SVA-infected animals can shed the virus through faecal, oral or nasal routes. The virus can be detected in oral fluid up to 4 weeks post infection (wpi), and viable virus can be detected in oral fluid up to $3 \mathrm{wpi}$ (12). Additionally, rodents and houseflies may also play a role in SVA epidemiology. SVA nucleic acids were detected in houseflies collected from affected farms and from a farm with no history of vesicular disease. Detection of SVA in mice and housefly samples and recovery of viable virus from mouse faeces and small intestine suggest that these pests may play a role in the epidemiology of SVA (13). Since no vaccines or specific treatments are available for SVA infection, sanitary practices should include prophylactic and control measures applied to the herd, the sick animals and the environment. Measures should be taken to avoid the introduction of SVA into pig herds, and in those where the infection has been established to avoid virus dissemination among animals of different pig-producing categories present in the same herd. The introduction of SVA can be prevented by adopting strict biosecurity measures. The entry of vehicles, equipment, people, animals and food into pig production facilities must be strictly controlled $(1,13)$. Livestock trailers and carcass-removal equipment were subjectively assessed as the most likely routes of SVA introduction in a risk-assessment study (1). Preferably, pigs should be transported by vehicles or livestock trailers that have not been in contact with vehicles, personnel or animals from Senecavirus-positive herds. On SVA-positive farms, in addition to the measures previously mentioned, strict cleaning and disinfection of the facilities and equipment have to be adopted. The effectiveness of disinfectants against SVA is not yet well-known. Since the clinical signs caused by the SVA infection are very similar to those caused by FMDV, control measures should be adopted that take into account the possibility of FMD virus circulation. SVA circulation should be monitored through diagnostic examinations conducted on biological samples from symptomatic and asymptomatic pigs from different sites of the production unit. The adoption of these measures does not rule out the officially recommended procedures.

It is well known that some non-human viruses have antitumor potential due to their lack of immunogenicity and capacity to cause disease in humans (14). An example of such a virus is SVV, which is the first oncolytic picornavirus to be tested in humans and to penetrate solid tumours through the vascular system, unlike many other oncolytic viruses. SVV has potential cytolytic activity and high selectivity for tumour cell lines with neuroendocrine properties versus adult normal cells (25). In vitro cytotoxicity and virus production assays have been performed on several tumour cell lines to determine the relationship between cyto- 
toxicity and virus replication. Viral replication assays proved that SVV was capable of invading and replicating over time in tumour cells, but not in normal cells, such as hepatocytes. It was found that systematically administered SVV resulted in a remarkable decrease in tumour growth (25). Liu et al. (17) examined the therapeutic efficacy of SVV and the mechanism of tumour cell infection in pediatric malignant gliomas. SVV was able to directly lyse tumour cells cultured from patient tumours and to infect glioblastoma cells grown as neurospheres. As a result, this virus eliminated about $80 \%$ of xenograft tumours after 4 weeks of treatment. The authors conclude that SVV possesses strong antitumor activity against pediatric malignant gliomas and utilizes $\alpha 2,3$-linked and $\alpha 2,6$-linked sialic acids as mediators of tumour cell infection (17). Others studies on the oncolytic activity of SVV against 23 pediatric cancer cell lines in the Pediatric Preclinical Testing Program using in vitro and in vivo models showed that neuroblastoma and alveolar rhabdomyosarcoma (RMS) were the most sensitive tumour types (20). Summarizing the potential antitumor activity of Senecavirus in human cancer therapy, it can be stated that SVV appeared to be an ideal oncolytic virus given its ability to penetrate tumours and rapidly replicate, as well as its non-integrating RNA genome, nonpathogenicity, low incidence of pre-existing immunity in humans and selectivity for tumours expressing neuroendocrine features (3).

To conclude, the aim of this paper was to draw the attention of veterinarians, including clinicians, pathologists and researches, to an apparently novel clinical-pathologic condition linked to the new emerging pathogen Senecavirus A. The major current concern is the similarity of the clinical signs of SVA to those of other vesicular swine diseases because one of them, FMD, is an OIE-listed disease. The regulatory impact associated with the notification of an OIE-listed disease can be very negative for the pig production of a given country or region, including the official investigation, banning of animal movements, restriction of human movements and export restrictions on products of animal origin. In consequence, an early warning of the clinical condition by the attending farm veterinarian is of considerable value, and immediate sampling and laboratory testing for FMD and other vesicular diseases of swine are obligatory. To date, minimal data are available on the causative role of SVA in disease. A study performed by Montiel et al. (19) provided evidence that SVA can cause vesicular disease in swine. The authors were able to induce vesicular lesions in 9-week-old pigs inoculated via the intranasal route. Evidence that SVA can cause vesicular disease in swine has also been obtained by inoculation of finishing pigs with SVA. The inoculation of such pigs with SVA resulted in clinical signs and lesions that were consistent with descriptions of field cases of SVA (12). However, the association of SVA with disease is still speculative at this time because SVA can be isolated from normal pigs, and other viruses are frequently detected in samples from clinically affected pigs in which SVA was found (2). In addition, many other questions remain to be answered regarding (a) specific features of the virus, including its biological and molecular evolution, $\mathrm{pH}$ stability, receptors and co-receptors, cellular macromolecules, replication cycle, environmental survival; (b) SVA epidemiology, including such questions as how the virus has been disseminated to other countries, nonswine species reservoirs and vectors (probably through vertical transmission); (c) pathogenicity in piglets; and (d) host immunological response, including protective antibody titres in colostrum. The available data indicate that the SVA infection is currently limited to the United States, Canada, Brazil, China and Thailand. Descriptions of the SVA infection in Asia suggest that the virus is not restricted to a specific geographic region and may be distributed on a global scale in the future. Epidemiological investigations should therefore be conducted in countries in which the virus has never been detected, especially in those with extensive pig production, where SVA infection may have more economic relevance. SVA has demonstrated again that the risk of emerging infectious diseases in swine populations is high and that emerging diseases of swine have a significant potential impact on the productivity and economics of the pork industry. Such events emphasize the importance of basic and applied research and the need for emergency preparedness to develop and implement methods for early detection and containment of emerging infectious diseases.

\section{References}

1. Baker K. L., Mowrer C., Canon A., Linhares D. C., Rademacher C., Karriker L. A., Holtkamp D. J.: Systematic epidemiological investigations of cases of Senecavirus A in US swine breeding herds. Transbound. Emerg. Dis. 2017, 64, 11-18.

2. Bracht A. J., O'Hearn E. S., Fabian A. W., Barette R. W., Sayed A.: Real-time reverse transcription PCR assay for detection of Senecavirus A in swine vesicular diagnostic specimens. PLoS ONE 2016, 11, e0146211, doi: 10.1371/ journal.pone.0146211, eCollection 2016.

3. Burke J. M.: Oncolytic Seneca Valley virus: past perspectives and future directions. Oncolytic Virother. 2016, 5, 81-89, doi: 10.2147/OV.S96915.

4. Cameron R.: Diseases of skin, [in:] Straw B. E., Zimmermann J. J., D'Allaire S. et al. (eds.): Diseases of swine, $9^{\text {th }}$ ed. Ames, IA: Blackwell 2006, p. 179-198. 5. Canning P., Canon A., Bates J. L., Gerardy K., Linhares D. C., Pineyro P. E., Schwartz K. J., Yoon K. J., Rademacher C. J., Holtkamp D., Karriker L.: Neonatal mortality, vesicular lesions and lameness associated with Senecavirus A in a U.S. sow farm. Transbound. Emerg. Dis. 2016, 63, 373-378.

6. Chen Z., Yuan F., Li Y., Shang P., Schroeder R., Lechtenberg K., Henningston J., Hause B., Bay J., Rowland R. R., Clavijo A., Fang Y.: Construction and characterization of a full-length cDNA infectious clone of emerging porcine Senecavirus A. Virology 2016, 497, 111-124.

7. Dall Agnol A. M., Otonel R. A., Leme R. A., Alfieri A. A., Alfieri A. F.: A TaqManbased qRT-PCR assay for Senecavirus A detection in tissue samples of neonatal piglets. Mol. Cell. Probes 2017, 33, 28-31.

8. Gibbs E. P., Stoddard H. L., Yedloutching R. J., House J. A., Legge M.: A vesicular disease of pigs in Florida of unknown etiology. Florida Vet. J. 1983, $12,25-27$.

9. Gimenez-Lirola L. G., Rademacher C., Linhares D., Harmon K., Rotolo M., Sun Y., Baum D. H., Zimmerman J., Pineyro P.: Serological and molecular detection of Senecavirus A associated with an outbreak of swine idiopathic vesicular disease and neonatal mortality. J. Clin. Microbiol. 2016, 54, 2082-2089 . 
10. Guo B., Pineyro P. E., Rademacher C. J., Zheng Y., Li G., Yuan J., Hoang H., Gauger P. C., Madson D. M., Schwartz K. J., Canning P. E., Arruda B. L., Cooper V. L., Baum D. H., Linhares D. C., Main R. G., Yoon K. J.: Novel Senecavirus A in swine with vesicular disease, United States, July 2015. Emerg. Infect. Dis. 2016, 22, 1325-1327.

11. Hales L. M., Knowles N. J., Reddy P. S., Xu L., Hay C., Hallenbeck P. L.: Complete genome sequence analysis of Seneca Valley virus-001, a novel oncolytic picornavirus. J. Gen. Virol. 2008, 89, 1265-1275.

12.Joshi L. R., Fernandes M. H., Clement T., Lawson S., Pillatzki A., Resende T. P., Vannucci F. A., Kutish G. F., Nelson E. A., Diel D. G.: Pathogenesis of Senecavirus A infection in finishing pigs. J. Gen. Virol. 2016, 97, 3267-3279.

13. Joshi L. R., Mohr K. A., Clement T., Hain K. S., Myers B., Yaros J., Nelson E. A., Christopher-Hennings J., Gava D., Schaefer R., Caron L., Dee S., Diel $D$. G.: Detection of the emerging picornavirus Senecavirus A in pigs, mice, and houseflies. J. Clin. Microbiol. 2016, 54, 1536-1545.

14. Koppers-Lalic D., Hoeben R. C.: Non-human viruses developed as therapeutic agent for use in humans. Rev. Med. Virol. 2011, 21, 227-239.

15. Leme R. A., Oliveira T. E., Alcantara B. K., Headley S. A., Alfieri A. F., Yang M., Alfieri A. A.: Clinical manifestation of Senecavirus A infection in neonatal pigs, Brasil 2015. Emerg. Infect. Dis. 2016, 22, 1238-1241.

16. Leme R. A., Zotti E., Alcantara B. K., Oliveira M. V., Freitas L. A., Alfieri A. F., Alfieri A. A.: Senecavirus A: an emerging vesicular infection in Brazilian pig herds. Transbound. Emerg. Dis. 2015, 62, 603-611.

17. Liu Z., Zhao X., Mao H., Baxter P. A., Huang Y., Yu L., Wadhwa L., Su J. M., Adesina A., Perlaky L., Hurwitz M., Idamakanti M., Police S. R., Hallenbeck P. L., Hurwitz R. L., Lau C. C., Chintagumpala M., Blaney S. M., Li X. N.: Intravenous injection of oncolytic picornavirus SVV-001 prolongs animal survival in a panel of primary tumor-based orthotopic xenograft mouse models of pediatric glioma. Neuro Oncol. 2013, 15, 1173-1185.

18. Montgomery J. F., Oliver R. E., Poole W. S.: A vesiculo-bullous disease in pigs resembling foot-and-mouth disease. I. Field cases. N.Z.Vet J. 1987, 35, 21-26.

19. Montiel N., Buckley A., Guo B., Kulshreshtha V., VanGeelen A., Hoang H., Rademacher C., Yoon K. J., Lager K.: Vesicular disease in 9-week-old pigs experimentally infected with Senecavirus A. Emerg. Infect. Dis. 2016, 22, 1246-1248.

20. Morton C. L., Houghton P. J., Kolb E. A., Gorlick R., Reynolds C. P., Kang M. H., Maris J. M., Keir S. T., Wu J., Smith M. A.: Initial testing of replication competent Seneca Valley virus (NTX-010) by the pediatric preclinical testing program. Pediatr. Blood Cancer 2010, 55, 295-303.

21. Munday B. L., Ryan F. B.: Vesicular lesions in swine-possible association with the feeding of marine products. Aust. Vet. J. 1982, 59, 193.

22. Pasma T., Davidson S., Shaw S. L.: Idiopathic vesicular disease in swine in Manitoba. Can. Vet. J. 2008, 49, 84-85.
23. Paton D. J., Gubbins S., King D. P.: Understanding the transmission of footand-mouth disease virus at different scales. Curr. Opin. Virol. 2018, 28, 85-91.

24. Qian S., Fan W., Qian P., Chen H., Li X.: Isolation and full-genome sequencing of Seneca Valley virus in piglets from China, 2016. Virol. J. 2016, 13, 173, doi: 10.1186/s12985-016-0631-2.

25. Reddy P. S., Burroughs K. D., Hales L. M., Ganesh S., Jones B. H., Idamakanti N., Hay C., Li S. S., Skele K. L., Vasko A. J., Yang J., Watkins D. N., Rudin C. M., Hallenbeck $P$. L.: Seneca Valley virus, a systematically deliverable oncolytic picornavirus, and the treatment of neuroendocrine cancers. J. Natl. Cancer Inst. 2007, 99, 1623-1633.

26. Saeng-Chuto K., Rodtian P., Temeeyasen G., Wegner M., Nilubol D.: The first detection of Senecavirus A in pigs in Thailand, 2016. Transbound. Emerg. Dis. 2018, 65, 285-288, doi: 10.1111/tbed.12654.

27. Saporiti V., Fritzen J. T. T., Feronato C., Leme R. A., Alfieri A. F., Alfieri A. A.: A ten years (2007-2016) retrospective serological survey for Seneca Valley virus infection in major pig producing states of Brazil. Vet. Res. Commun. 2017, 41, 317-321.

28. Segales J., Barcellos D., Alfieri A., Burrough E., Marthaler D.: Senecavirus A: an emerging pathogen causing vesicular disease and mortality in pigs? Vet. Pathol. 2017, 54, 11-21.

29. Sensi M., Catalano A., Tinaro M., Mariotti C., Panzieri C., Marchi S., Costarelli $S$.: Idiopathic vesicular disease (IVD): a case report in the centre of Italy. Proc. International Pig Veterinary Society 2010; O005.

30. Singh K., Corner S., Clark S. G., Scherba G., Fredrickson R.: Seneca Valley virus and vesicular lesions in a pig with idiopathic vesicular disease. J. Vet. Sci. Technol. 2012, 3, 6 .

31. Vannucci F. A., Linhares D. C., Barcellos D. E., Lam H. C., Collins J., Marthaler D.: Identification and complete genome of Seneca Valley virus in vesicular fluid and sera of pigs affected with idiopathic vesicular disease, Brasil. Transbound. Emerg. Dis. 2015, 62, 589-593.

32. Wang L., Prarat M., Hayes J., Zhang Y.: Detection and genomic characterization of Senecavirus A, Ohio, USA, 2015. Emerg. Infect. Dis. 2016, 22, 1321-1323.

33. Wu Q., Zhao X., Bai Y., Sun B., Xie Q., Ma J.: The first identification and complete genome of Senecavirus A affecting pig with Idiopathic Vesicular Disease in China. Transbound. Emerg. Dis. 2017, 64, 1633-1640, doi: 10.1111/ tbed.12557.

34. Yang M., van Bruggen R., Xu W.: Generation and diagnostic application of monoclonal antibodies against Seneca Valley virus. J. Vet. Diagn. Invest. 2012, $24,42-50$

35. Zhao X., Wu Q., Bai Y., Chen G., Zhou L., Wu Z., Li Y., Zhou W., Yang H., MaJ.: Phylogenetic and genome analysis of seven Senecavirus A isolates in China. Transbound. Emerg. Dis. 2017, 64, 2075-2082, doi: 10.1111/tbed.12619.

Corresponding author: dr hab. Wiesław Niedbalski, assoc. prof., Wodna 7 , 98-220 Zduńska Wola; e-mail: wieslaw.niedbalski@piwzp.pl 